\title{
STUDIES ON THE TOXICOLOGICAL EFFECTS OF ENGINEERED NANOPARTICLES IN ENVIRONMENT - A REVIEW
}

\author{
Radhika Rajasree S.R. ${ }^{1}$, Ganesh Kumar V., Stanley Abraham L. and Inbakandan D. \\ Centre for Ocean Research, Sathyabama University \\ Jeppiaar Nagar, Rajiv Gandhi Road \\ Chennai - 600119. \\ E-mail: ${ }^{1}$ radhiin@gmail.com
}

\section{ABSTRACT}

This paper considers the standard ecotoxicity tests done so far for assessing the hazards of engineered nanoparticles and potential negative effects that engineered nanoparticles may have on environment. Research and development in nanotechnologies increase strongly and attract substantial funding, but environmental consequences of resulting materials and applications are poorly known. We prepared nanoparticles by continuous sonication and by ultra filtration. Artemia salina was differentiated to five life stages based on certain easily distinguished features and were exposed to different concentrations of Titanium Dioxide and Fullerene using 48 hours acute toxicity testing. Images of the particle solutions were recorded using TEM and the median lethal concentration was determined in each life stage. Exposure to sonicated nanoparticles shows varied mortalities in different stages of Artemia salina where as filtered solutions showed increasing mortality with increase in concentration. We conclude that uncontrolled and unobserved release of these nanoparticles either as byproducts or medical wastes, could have a large negative consequence on the aquatic and terrestrial organisms, particularly on the humans.

Keywords: Engineered nanoparticles, toxicity testing, Artemia salina, Negative effects.

\section{INTRODUCTION}

Nanotechnology is the development and manufacture of materials in the nanometer size range (at least one dimension less than $100 \mathrm{~nm}$ ) and their application. Nanoparticles deserve special attention, because compounds in this miniature size range have chemical properties that differ from those of their larger counterparts. As the size of the particle decreases, the number of atoms exposed on the surface and the amount of energy available for release increase (Banfield and Navrotsky, 2001). Due to their small size, a relatively large proportion of the atoms and molecules making up the particles are exposed at the particle surface compared to larger particles. This structural difference coupled with the relatively large surface area per unit mass of nanoparticles allow such materials to exhibit properties that differ from bulk chemicals, making them useful in a wide variety of applications including electronics, paints, cosmetics, medicines, foods, textiles and environmental remediation. Today, nano-scale zinc oxides are used in sunscreen lotions and scratch-resistant glass while carbon nanotubes are incorporated into tennis rackets, and nano-engineered chemical treatments performed on fabrics to render them stain-resistant The National Science Foundation has estimated that nanotechnology applications may be valued at more than 1 trillion dollars in the global economy by 2015 (Bergeson and Auerbach, 2004). Apart from consumer products, nanomaterials are being tested for medical and environmental uses.

\section{A. Health concerns of nanoparticle toxicity}

Research has shown that many types of nanomaterials can be toxic to human tissue and cell cultures, resulting in increased oxidative stress, inflammatory cytokine production, DNA mutation and even cell death (Oberdoster et al., 2005a). Materials are more readily taken up by the human body than larger sized particles and are able to cross biological membranes that larger sized particles normally cannot (Holsapple et al., 2005). Once in the blood stream, nanomaterials are transported around the body and can be absorbed into vital organs including the heart, kidney, liver and spleen (Oberdoster et al., 2005b).

Unlike larger particles and materials, nanomaterials may be transported within cells and be taken up by cell mitochondria( Li et al., 2003) and the cell nucleus (Gieser et al.,2005), where they can cause major structural damage. The small size, greater surface area and greater chemical reactivity of nanomaterials results in increased production of reactive oxygen species, including free radicals ( $\mathrm{Nel}$ et 
al., 2006). Production of reactive oxygen species has been found in a diverse range of nanomaterials including nanoparticle metal oxides (Dunford et al.,1997; Warmer et al., 1997; Savic et al., 2003; Hussian et al., 2005; Long et al.,2006 ; Zhang and Sun, 2003) commonly used in sunscreens and cosmetics and carbon fullerenes (Yamakoshi, et al., 2004) that are used in some face creams and moisturizers. Reactive oxygen species and free radical production is one of the primary mechanisms of nanotoxicity; it may result in oxidative stress, inflammation, and consequent damage to proteins, membranes and DNA ( $\mathrm{Nel}$ et al., 2006).

There is evidence that nanomaterials can enter the human body through several mediums. The human skin, intestinal tract, and lungs are always in direct contact with the environment (Hoet et al., 2004). Some toxicological studies have been conducted in relation to the inhalation of NP made from low toxicity materials such as carbon black (Li et al., 1999), $\mathrm{TiO}_{2}$ (Ferin et al., 1992) and polystyrene (Brown et al., 2001). Such studies demonstrate that the toxicity of these materials is related to their ability to induce oxidative stress and inflammation in the lung leading to impacts on lung and cardiovascular health. The cells of the body contain a number of antioxidant defense molecules (e.g. glutathione and vitamin E) that protect cells against reactive oxygen species (ROS) and free radicals that due to their electrophillic properties damage proteins, lipids and DNA. Such ROS and free radicals include superoxide anion radicals (O2 -.) and hydroxyl radicals $(\mathrm{OH}$.$) and are generated at the surface of NP (Stone$ et al., 1998, Wilson et al., 2002). Depletion of antioxidant defense molecules by these ROS and production of free radicals lead to oxidative stress and damage to cells. Nanoparticles causing oxidative stress may also lead to the production of reactive nitrogen, sulphur and other species (i.e. RNS, RSS and others) stressing the body in a similar manner to the effect of ROS. In the case of RSS (Giles and Jacob, 2002), reactive sulphur substances such as thiyol radicals and disulphides can oxidize and ultimately inhibit thiol proteins and enzymes.

Oxidative stress can also cause cell damage and activate inflammation (Donaldson et al., 2000) . This involves activation of various white blood cells within the immune system. Such cells include macrophages that migrate to the site of particle deposition and then engulf the particles by phagocytosis. The macrophages then remove the particles from the lung surface by either moving out of the airways along with mucus, or by migrating into the body's lymph nodes. Successful particle clearance allows the inflammation to subside and any tissue damage to be repaired. Unsuccessful particle clearance leads to persistent inflammation and oxidative stress that causes cellular damage leading to a variety of disease effects (Donaldson et al., 2003). Acute effects associated with particulate air pollution result in increased hospitalization and deaths from both respiratory and cardiovascular diseases. Such effects have been attributed to airborne nanoparticles (Peters et al., 1997). Acute effects tend to affect people who are susceptible due to pre-existing inflammatory diseases. Chronic effects associated with other respirable particles, such as environmental particulate air pollution, crystalline silica (alpha-quartz) and asbestos fibres, include fibrosis lung tissue making breathing difficult) and cancer.

The long term health effects of respirable nanoparticles as yet have not been elucidated. Epidemiological evidence from industrial processes, such as the manufacture of carbon black, where workers may potentially be exposed to nanoparticles, is not clear-cut. Studies which investigate the ability of nanoparticles made from low toxicity materials to generate oxidative stress and inflammation suggest that potency is dependent upon their surface area (Brown et al., 2001, Duffin et al., 2002). Furthermore, studies that compare low toxicity materials and particles made from more noxious substances, such as nickel or alphaquartz, demonstrate that biological reactivity is a function of both surface reactivity and surface area (Duffin et al., 2002). For non-spherical particles such as fibres, it is well recognized that dimensions and durability are important factors in determining their ability to induce fibrosis and cancer (Warheit et al., 1995, Donaldson et al., 1989). It is conceivable that these properties will also be relevant to nanoparticles such as nanotubes, nanowhiskers and nanofibres. For new, more novel forms of engineered nanoparticles it is likely that a combination of the factors described above will be important in determining their ability to induce adverse effects in human and wider environmental systems.

Experiments on animals indicate that nanoparticles do affect the cell structure and in some 
cases even reflect the inflammation in organs leading to carcinogenic developments (Driscoll et al., 1997). Another consideration is the development of nanotech-associated health complications in workers engaged directly in the production of these particles (Dowling, 2004; Lyman, 2003; Wolfgang, 2004). The direct and sustained exposure to these particles at various stages makes them the most vulnerable category. Without stringent safety measures and containment procedures, nanoparticles released through exhaust, leaks, cleaning and maintenance of the facility would saturate the working area, increasing the level of exposure to the worker (Lyman, 2003).

\section{B. Environmental concerns of nanoparticles toxicity}

In addition to the health hazards that nanoparticles may pose when directly inhaled, ingested, or applied to the human body, general environmental risks may also exist when such particles enter the soil, the water, or the air. Many of the current and intended uses of nanoparticles are in relation with environment including remediation (removal of pollutants from contaminated water or soil where large quantities are used in e.g. permeable reactive barrier), water treatment filters and control of algal growth in water systems (Biswas and Wu, 2005). The rapid growth of nanotechnologies will also lead to increased accidental and purposeful release of nanoparticles into the environment. It is, therefore, important that overall impacts and risks of newly engineered nanoparticles released into the environment are addressed (Colvin, 2003, Nature, 2003, Oberdorster et al 2005). A study by Oberdorster et al. (2004) on the effects of buckyballs on bass proved that other species are also highly vulnerable to the effects of nanomaterials. In this same study, it was also observed that nanomaterials also affected microbes; the result was a $100 \%$ mortality rate. Although there are no other significant studies to substantiate this further, it is logical that nanomaterials could affect the ecosystem.

When nanoparticles are released into the environment they may be released into air, water or into soil allowing access to a variety of different species ranging from single celled organisms such as bacteria and algae through to more complex vertebrates such as fish and aquatic mammals ( Oberdorster, 2004, Oberdorster et al., 2006). Impacts on any of the organisms within the ecosystem may have consequences on the remainder of the ecosystem by affecting food chains and interactions between different species. It is, therefore, important to assess the fate and distribution of nanoparticles released into the environment in order to ascertain which environments and species are most at risk of significant exposure. Fate and distribution are likely to be different depending on the chemical and physical characteristics of the particles in relation to hydrophobicity and particle surface charge. As yet, we have been unable to identify any studies that have demonstrated the ability to track nanoparticles in the environment or to assess their fate. In addition to determining the fate and distribution of nanoparticles in the environment, it is also essential to assess their potential toxicity to a wide range of species (Lovern et al., 2006).

\section{Nanotoxicity studies in terrestrial organisms}

To date in relation to ecotoxicology, the effects of nanoparticles on terrestrial microorganisms has been the area most widely studied. For example, silver nanoparticles can be used in wound dressings, although it is not clear whether these antimicrobial effects are simply due to the silver rather than the particulate form. However, Sondi and Salopek-Sondi (2004) provided evidence of silver nanoparticles accumulation in the membrane of the bacterium Escherichia coli causing cell wall pits leading to cell permeability changes and ultimate death. Lee, 2005 recently demonstrated that UV irradiation of $\mathrm{TiO}_{2}$-coated multi-walled nanotubes (MWNTs) was more useful at killing bacterial endospores than either UV light alone or UV irradiated $\mathrm{TiO}_{2}$ particles. However, the composite of nanotubes and $\mathrm{TiO}_{2}$ appeared to cause endospore aggregation so that some of the spores were protected and survived, a phenomenon not observed with the other treatments. Magnetic nanoparticles have also been developed as a tool to remove bacteria from aquatic environments (Watson et al., 2000). The large surface area of nanoparticles makes them ideal for use as absorbents and so a number of products are being developed for the destruction or removal from the environment of bacteria, including biological warfare agents (Koper \& Klabunde, 2000).

In addition to effects on bacteria, $\mathrm{TiO}_{2}$-coated hollow glass beads have been shown to inhibit the photosynthetic activity of cyanobacteria, and diatoms, suggesting potential useful applications in preventing excessive algal growth (Kim and Lee, 2005). Yang and 
Watts (2005) investigated the phytotoxicity of $13 \mathrm{~nm}$ aluminium nanoparticles (Al-NPs) on root growth by the seeds of five different plant species. The Al-NPs inhibited root growth at high concentrations (2mg ml-1), while larger Al particles of $200-300 \mathrm{~nm}$ had no effect. The inhibiting effects on root growth were decreased by the addition of dimethyl sulphoxide (DMSO), a molecule that scavenges free radicals such as hydroxyl radicals, suggesting that oxidative stress may play a role in the effects of the NP on root elongation. The toxicity of copper NPs $(23.5 \mathrm{~nm})$ was assessed in vivo based on $\mathrm{LD}_{50}$, morphological changes, pathological examinations and blood biochemical indices of experimental mice (Chen et al., 2006).

In addition, acute tests on other target organisms have not as yet been published, and so there is still a lack of knowledge in this area. It is clear that different nanomaterials and test procedures are factors in the results obtained, but these need to be further explored.

\section{Nanotoxicity studies in aquatic organisms}

Aquatic environments may also be threatened by pollution from nanomaterials. Oberdörster (2004) exposed juvenile largemouth bass to $\mathrm{C}_{60}$ fullerenes and investigated the resulting induced oxidative stress. Her research indicated a trend toward a decrease of glutathione (GSH) in the gills and an increase of lipid peroxidation in the liver. Gills are important in extracting oxygen from ambient water and are priority organs in xenobiotic exposure. Redox-active particles encountered by the gills should therefore induce antioxidant enzyme production and consume GSH. Meanwhile, the brain has a blood-brain barrier that prohibits exposure of the brain to xenobiotics. Lipid peroxidation in the brain would be an indicator that nanomaterials have reached this organ, but unfortunately there is no evidence indicating that nanomaterials reach the brain of fish (Oberdörster et al. 2004). Yamago et al. (1995) studied the in vivo biological behavior of a 14C-labeled water-miscible $\mathrm{C}_{60}$ fullerene in rats. Fullerenes administrated orally were easily eliminated in the feces, but those injected intravenously were retained in the body after 1 week. The intravenously injected fullerenes were distributed mainly in the liver ( $91.7 \%$ of dose), and simultaneously some were able to penetrate slightly the blood-brain barrier. Nanoparticles were also detected in the brain, testis, liver, and blood of Oriziyas latipes (Kashiwada,2006) . Concentrations of nanoparticles in the blood of male and female medaka were 16.5 and $10.5 \mathrm{ng} / \mathrm{mg}$ blood protein, respectively. Liver cells of rainbow trout Oncorhynchus mykiss exposed to $\mathrm{TiO}_{2} \mathrm{NPs}$ showed minor fatty change and lipidosis, and some hepatocytes showed condensed nuclear bodies (Federici et al.,2007). Lovern and Klaper (2006) treated Daphnia magna with $\mathrm{C}_{60}$ or $\mathrm{TiO}_{2}$. The particles were prepared by either sonication in medium for 30 minutes to break up the aggregates, or by solubilisation in the organic solvent tetrahydrofuran (THF). The sample prepared in THF was filtered and evaporated in order to attempt to remove the solvent from the particles (see below) prior to addition to the invertebrates. The $\mathrm{TiO}_{2}$ and the $\mathrm{C}_{60}$ particles were more potent at killing the organisms when prepared in THF than when prepared by sonication, and the $\mathrm{C}_{60}$ was more potent than the $\mathrm{TiO}_{2}$. Lovern and co-workers have also observed that nanoparticles induced irregular swimming behaviour of Daphnia magna.

\section{E. Fullerene and titanium dioxide toxicity}

Exposure to titanium dioxide nanoparticle, used in large numbers of sunscreens, cosmetics and personal care products, has been shown to cause far greater cell damage than larger particles of titanium dioxide. It has been demonstrated that $500 \mathrm{~nm}$ titanium dioxide particles have only a small ability to cause DNA strand breakage, whereas exposure to $20 \mathrm{~nm}$ particles of titanium dioxide causes complete destruction of supercoiled DNA, even at low doses and in the absence of exposure to UV (Donaldson, 1995). Also in the absence of UV light, in vitro exposure to nanoparticle titanium dioxide resulted in the production of reactive oxygen species in human brain cells although it is not yet known whether these reactive oxygen species damage brain neurons. Pilot data indicate that nanoparticle titanium dioxide results in cell death in cultured neurons at concentrations 20ppm after 24 hours exposure (Long et al., 2006).

The toxicity of fullerenes, currently being used in some face creams and moisturizers, remains poorly understood. However some early experiments have demonstrated the potential for some forms of fullerenes to be toxic. Carbon fullerenes (buckyballs) have been found to cause brain damage in fish (Oberdoster, 2004), kill water fleas and have bactericidal properties (Fortner, 2005). Even low levels of exposure to water soluble fullerenes have been shown to be toxic to human liver cells carcinoma cells and dermal fibroblasts in vitro (Sayes, 2004). Fullerene-based amino acid 
nanoparticles have been found to decrease the viability of human epidermal keratinocytes and initiate a pro-inflammatory response (Rouse et al., 2006). Toxicity appears to be a function of both surface structure(Says, 2004) and also the extent of aggregation, where different solvents or emulsion bases are key variables in the formation of aggregates ( Rouse et al., 2006).

Fullerene has the capacity for oxyradical-induced lipid and protein damage, as well as impacts on total glutathione (GSH) levels, in largemouth bass exposed to $\mathrm{nC}_{60}$. Significant lipid peroxidation was found in brains of largemouth bass after $48 \mathrm{hr}$ of exposure to $0.5 \mathrm{ppm}$ uncoated $\mathrm{nC}_{60}$. $\mathrm{GSH}$ was also marginally depleted in gills of fish, and $\mathrm{nC}_{60}$ increased water clarity, possibly due to bactericidal activity (Oberdoster, 2004).

Centre for ocean Research of Sathyabama University experimented with two nanoparticles, $\mathrm{nTiO}_{2}$ and $\mathrm{nC}_{60}$ and assessed their toxicological effects on marine invertebrates, Artemia salina (Figure 9a-b) and Crassostrea madrasensis. The nanoparticles were prepared using two reliable methods namely, sonication and filtration, both of which resulted in a reduction in size of the regular sized particles. Sonicated fullerenes were observed to be much smaller in size than $\mathrm{nTiO}_{2}$ obtained by the same method (Figures 1-4). Also filtered nanoparticles are found to be smaller than their sonicated counterparts. The results of the present study are important because it is the first study to assess the impact of nanoparticles on the different life stages of Artemia salina and Crassostrea madrasensis. Amongst the two nanoparticles, the highest toxicity was observed in the second larval stage of Artemia exposed to $\mathrm{nC}_{60}$ data obtained from Probit analysis (Figure $5 \& 6$ ). Also filtered $\mathrm{TiO}_{2}$ was found to cause higher mortality than sonicated $\mathrm{TiO}_{2}$ (Figures $7 \&$ 8). Thus the size, method of preparation and the nature of particles was seen to account for toxicological effects.

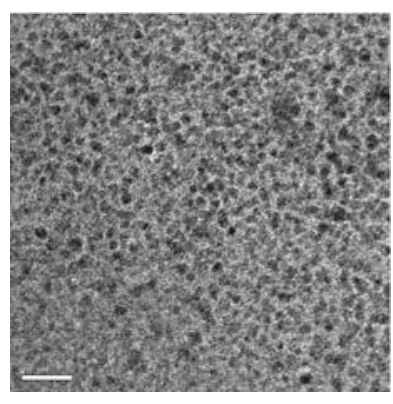

Fig. 1. Sonicated $\mathrm{nC}_{60}$

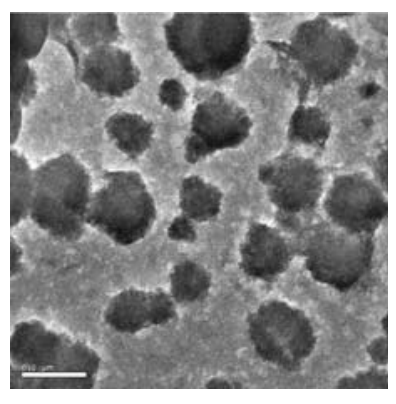

Fig. 2. Filtered $\mathrm{nC}_{60}$
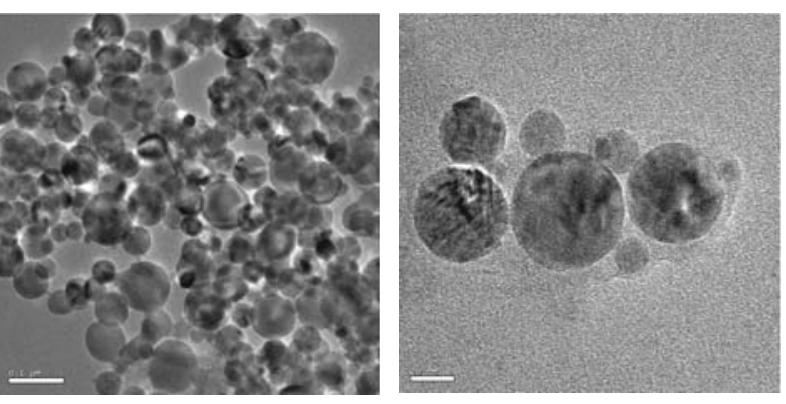

Fig. 3. Sonicated nTiO

Fig. 4. Filtered $\mathrm{nTiO}_{2}$
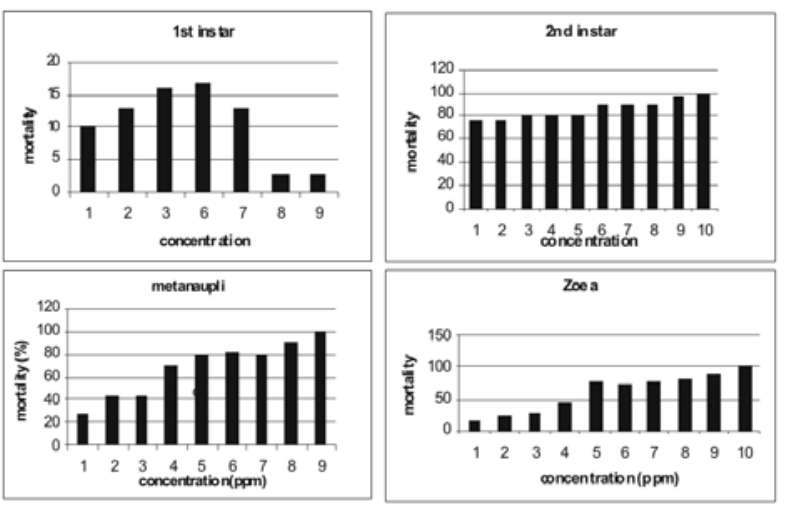

Fig. 5. Mortality of A.salina life stages on exposure to sonicated $\mathrm{C}_{60}$

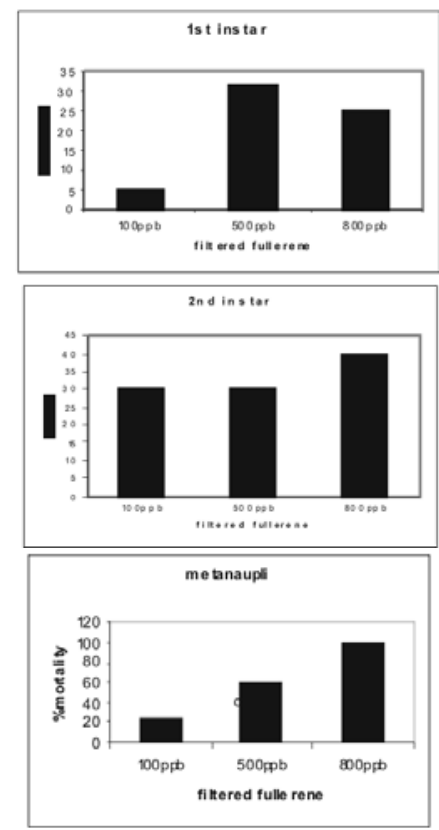

Fig. 6. Mortality of A.salina life stages on exposure to filtered $\mathrm{C}_{60}$ 


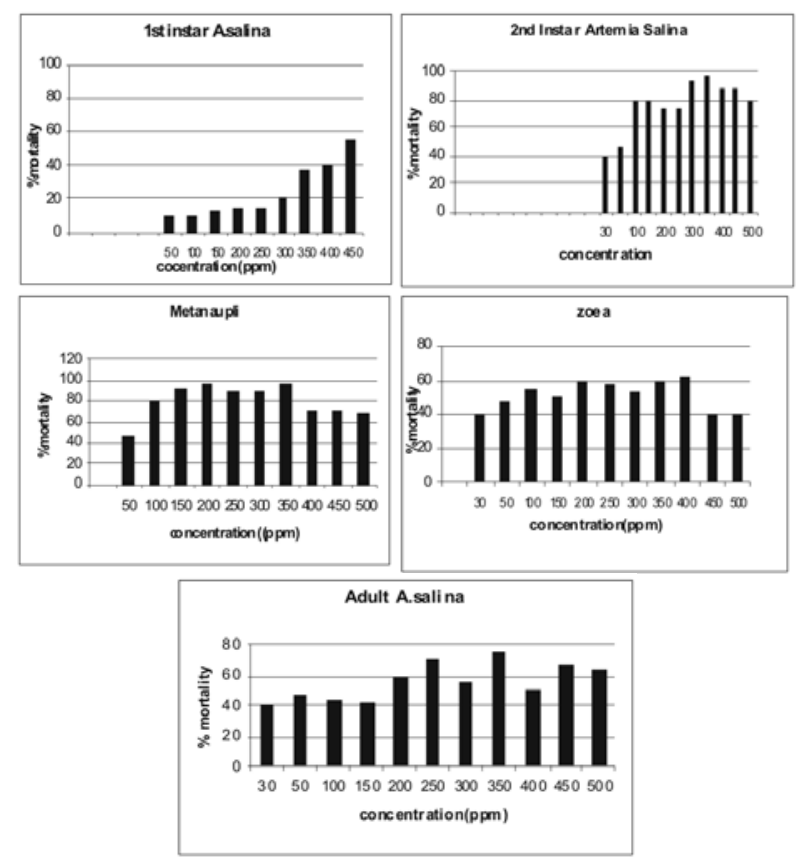

Fig. 7. Mortality of A.salina life stages on exposure to sonicated $\mathrm{TiO}_{2}$

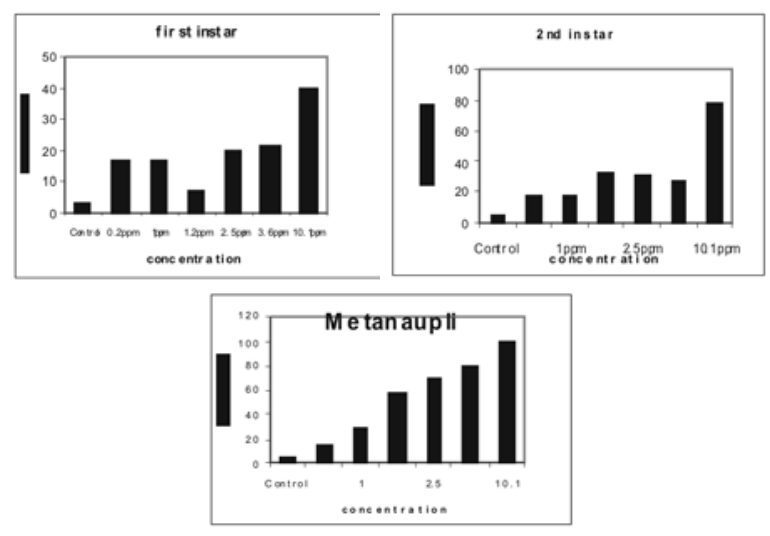

Fig. 8. Mortality of A.salina life stages on exposure to filtered $\mathrm{TiO}_{2}$
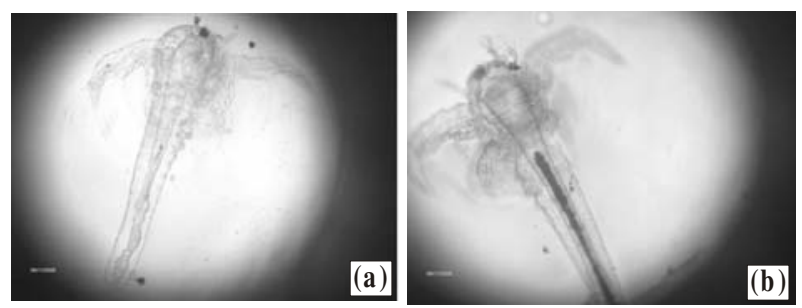

Fig 9a-b. Metanauplii stage of A.salina before and after exposure, intestine filled with particles

\section{CONCLUSION}

The result of the present study gains significance from the fact that it is one of the first to examine the impact of nanoparticles on various life stages of a marine invertebrate. This work has shown that standard toxicity testing can be used to examine nanoparticle toxicity in lower level of organisms. Artemia salina is one of the most valuable test organisms available for marine ecotoxicity testing as it is widely used as a nutritious live food source to the larvae of a variety of marine organism, which makes them the most convenient, least labor-intensive live food available for aquaculture and will be impacted greatly by release of nanoparticles into aquatic systems because of their high levels of interaction with the environment through non selective filter feeding. Understanding the potential impacts of these particles can help in identifying the most appropriate nanotechnology that will preserve the marine aquatic environment while also advancing medical and environmental technology. This result also attributes to our limited knowledge regarding the overall implications of these two nanoparticles on marine ecosystems As the nanoparticles have proved to be detrimental in this acute toxicity test, its effect in the long run is to be carefully analysed. Considering that the smaller nanoparticles turned out to be toxic in the present test, it cannot be excluded that the overall ecotoxicological potential will increase in future.

Hence it can be concluded that, the uncontrolled and unobserved release of these nanoparticles either as byproducts or medical wastes, could have a large negative consequence on the aquatic and terrestrial organisms, particularly on the humans. Hence, studies on the fate and effects of nanomaterials in the environment and in the living organisms are needed to more clearly define the benefits and potential risks of this promising technology.

\section{ACKNOWLEDGEMENT}

The study was carried out as part of the project "Studies on ecotoxicity of engineered nanoparticles on selected marine organisms" supported by Department of Biotechnology ,Govt. of India (BT/ PR10014/ NNT/ $28 / 91 / 2007$ ) and the financial assistance is gratefully acknowledged.

\section{REFERENCES}

[1] Banfield, J.F. \& Navrotsky, A. (2001). Nanocrystals and the environment - An introduction. In: J.F. Banfield \& 
A. Navrotsky (Eds.). Nanoparticles and the Environment, Reviews in Mineralogy and Geochemistry, Vol. 44 (pp. 11-I3). Washington, DC: Mineralogical Society of America anhd Geochemical Society.

[2] Bergeson, L.; Auerbach, B. (2004) Reading The Small Print. The Environ. Forum, 30-49.

[3] Biswas, P., and Wu, C. Y. (2005). Nanoparticles and the environment. J.Air Waste Manag. Assoc. 55,708-746.

[4] Brown, D. M., Wilson, M. R., MacNee, W., Stone, V., and Donaldson, K. (2001). Size-dependent proinflammatory effects of ultrafine polystyrene particles: a role for surface area and oxidative stress in the enhanced activity of ultrafines. Toxicol.Appl.Pharmacol. 175, 191-199.

[5] Cannuel R, Beninger P.G. (2006) Gill development, functional and evolutionary implications in the Pacific oyster Crassostrea Chem., 3-4, 375-388.

[6] Chen, Z. 2006, et al., Toxicol. Lett., 163,109-120.

[7] Colvin,V. (2003) The potential environmental impacts of engineered nanomaterials. Nature Biotechnol .21pp.1166-1170.

[8] Ding L, Stilwell J, Zhang T, Elboudwarej O, Jiang H and Selegue J.P.(2005). Molecular characterization of the cytotoxic mechanism of multiwall carbon nanotubes and nano-onions on human skin fibroblast. Nano Lett 5:2448-2464.

[9] Donaldson K, Beswick P, Gilmour P (1996). "Free radical activity associated with the surface of particles: a unifying factor in determining biological activity?" Toxicology Letters 88:293-298

[10] Donaldson K, Stone V, Clouter A, Renwick L, MacNee W. (2001). Ultrafine particles. Occup Environ Med 58: 211-216.

[11] Donaldson, K., Stone, V., Borm, P. J., Jimenez, L. A., Gilmour, P. S., Schins, R. P., Knaapen, A. M.,Rahman, I., Faux, S. P., Brown, D. M., and MacNee, W. (2003). Oxidative stress and calcium signaling in the adverse effects of environmental particles (PM10). Free Radic.Biol.Med. 34, 1369-1382.

[12] Donaldson, K., Stone, V., Gilmour, P. S., Brown, D. M., and MacNee, W. (2000) Ultrafine particles: mechanisms of lung injury. Phil.Trans.R.Soc.Lond. 358, 2741-2749.

[13] Dowling, A. (2004). Nanoscience and nanotechnologies: Opportunities and uncertainties- Summary and recommendations. London, UK: The Royal Society. Retrieved between Feb. 15 and Mar. 15, 2005, from www.nanotec.org.uk/finalReport/

[14] Driscoll, K.E., Deyo, L.C., Carter, J.M., Howard, B.W., Hassenbein, D., \& Bertram, T.A. (1997).Effects of particle exposure and particle-elicited inflammatory cells on mutation in rat alveolar epithelial cells. Carcinogenesis, 18(2), 423- 430.

[15] Duffin, R., Tran, C. L., Clouter, A., Brown, D. M., MacNee, W., Stone, V., and Donaldson, K. The importance of surface area and specific reactivity in the acute pulmonary inflammatory response to particles. Ann.Occup.Hyg. 46(Suppl. 1), 242-245. 2002

[16] Dunford R, Salinaro A, Cai L, Serpone N, Horikoshi S, Hidaka H, Knowland J (1997). "Chemical oxidation and DNA damage catalysed by inorganic sunscreen ingredients". FEBS Letters 418:87-90

[17] J, Geiss K, Schlager J (2005). "In vitro toxicity of nanoparticles in BRL $3 A$ rat liver cells". Toxicology In Vitro 19:975-983.

[18] Ferin, J., Oberdorster, G., and Penney, D. P. 1992. Pulmonary retention of ultrafine and fine particles in rats. Am.J.Respir.Cell Mol.Biol. 6, 535-542.

[19] Fortner J, Lyon D, Sayes C, Boyd A, Falkner J, Hotze E, Alemany L, Tao Y, Guo W, Ausman K, Colvin V, Hughes J (2005)." C60 in Water: Nanocrystal Formation and Microbial Response". Environmental Science and Toxicology 39(11); 4307-4316

[20] Geiser M, Rothen-Rutlshauser B, Knapp N, Schurch S, Kreyling W, Schulz H, Semmler M, Im H, Heyder J and Gehr P (2005). "Ultrafine particles cross cellular membranes by non-phagocytic mechanisms in lungs and in cultured cells". Environmental Health Perspectives 113(11):1555-1560. gigas (Bivalvia: Ostreidae). Mar Biol 149:547-563.

[21] Giles, Gl and Jacob, C. (2002). Reactive sulphur species: an emerging concept in oxidative stress. Biol.

[22] Hoet, P.H.M., Brüske-Hohlfeld, I., \& Salata, O.V. (2004). Nanoparticles-Known and unknown health risks. Journal of Nanobiotechnology, 2, 12, 1-15

[23] Holsapple M, Farland W, Landry T, Monteiro-Riviere N, Carter J, Walker N and Thomas K (2005). "Research strategies for safety evaluation of nanomaterials, Part II: Toxicological and safety evaluation of nanomaterials, current challenges and data needs". Toxicological Sciences 88(1):12-17

[24] Hund-Rinke, K. ; Simon, M..2006. Ecotoxic effect of photocatalytic active nanoparticles (TiO2) on algae and daphnids In: Environmental science and pollution research international : ESPR 13 (4):225-232

[25] Jia G, Wang H, Yan L, Wang $X$, Pei R and Yan T. 2005. Cytotoxicity of carbon nanomaterials: single-wall nanotube, multi-wall nanotube, and fullerene. Environ Sci Technol 39:1378-1383.

[26] Kamat J, Devasagayam T, Priyadarsini K, Mohan H, Mittal J. Oxidative damage induced by the fullerene 
C60 on photosensitization in rat liver microsomes. Chem Biol Interact 1998;114(3): 145-59.

[27] Kamat J, Devasagayam T, Priyadarsini K, Mohan H. derivatives and its possible biological implications. Toxicology .2000.155(1-3):55-61.

[28] Kashiwada ,Shosaku .2006 Distribution of nanoparticles in see-through Medaka (Oryza latipes) Environmental Health Perspectives. 114(11):1697-1702.

[29] Kim S-C, Lee D-K. 2005. Preparation of TiO2-coated hollow glass beads and their application to the control of algal growth in eutrophic water. Microchem $\mathrm{J} 80$ : 227- 232.

[30] Koper O, Klabunde KJ. 2000. Nanoparticles for the destructive sorption of biological and chemical contaminants. U.S. Patent 6, 057, 488; May 2.

[31] Lam CW, Jones JT, McCluskey R. \& Hunter RL. 2004. Pulmonary toxicity of single wall carbon nanotubes in mice 7 and 90 days after intratracheal instillation. Toxicol. Sci. 77: 126-134

[32] Li N, Sioutas C, Cho A, Schmitz D, Misra C, Sempf J, Wang M, Oberley T, Froines $J$ and Nel A (2003). "Ultrafine particulate pollutants induce oxidative stress and mitochondrial damage". Environmental Health Perspectives 111(4):455-460;

[33] Li X, Brown D, Smith S, MacNee W, Donaldson K. 1999. Short-term inflammatory responses following intratracheal instillation of fine and ultrafine carbon black in rats. Inhal Toxicol . 11:709-731.

[34] Long T, Saleh N, Pherat T, Schwartz C, Parker J, Lowry G, Veronesi B (2006). "Metal oxide nanoparticles produce oxidative stress in CNS microglia and neurons: physicochemical, cellular and genomic analysis". The Toxicologist:105 (\#513)

[35] Long T, Saleh N, Tilton R, Lowry G, Veronesi B (2006). "Titanium dioxide (P25) produces reactive oxygen species in immortalized brain microglia (BV2): Implications for nanoparticle neurotoxicity". Environmental Science \& Technology 40(14):4346-4352.

[36] Long T, Saleh N, Tilton R, Lowry G, Veronesi B (2006). "Titanium dioxide (P25) produces reactive oxygen species in immortalized brain microglia (BV2): Implications for nanoparticle neurotoxicity". Environmental Science \& Technology 40(14):4346-4352

[37] Lovern and Klaper (2006) Daphnia magna mortality when exposed to titanium dioxide and fullerene (C60) nanoparticles. Environmental Toxicology and Chemistry. Vol.23(4) 1132-1137.

[38] Lyman, J. (2003). Nanotech's green side: Cutting waste and risk, taming environmental fears.Small times. Retrieved between Feb15 \& Mar. 15, 2005, from www.smalltimes.com

document_display.cfm? document_id_6783.

[39] Lyon DY, Fortner JD, Hughes JB \& Alvarez PJ. 2005a. Impact of a C-60 water suspension on bacteria. Abstr. Pap. Am. Chem. S. 229: U910-U910 011.

[40] Lyon DY, Fortner JD, Sayes CM,Colvin VL \& Hughes JB. 2005b. Bacterial cell association and antimicrobial activity of a C-60 water suspension. Environ. Toxicol. Chem. 24: 2757-2762.

[41] Lyon DY, Adams LK, Falkner JC \& Alvarez PJJ. 2006. Antibacterial Activity of Fullerene Water Suspensions: Effects of Preparation Method and Particle Size Environ. Sci. Technol. 40: 4360-4366.

[42] Nel A, Xia T, Li N (2006). "Toxic potential of materials at the nanolevel". Science Vol 311:622-627.

[43] Oberdorster E. 2004 Manufactured nanomaterials (fullerenes, C60) induce oxidative stress in brain of juvenile largemouth bass. Environ Health Perspect 112:1058-1062.

[44] Oberdörster G, Maynard A, Donaldson K, Castranova V, Fitzpatrick J, Ausman K, Carter J, Karn B, Kreyling W, Lai D, Olin S, Monteiro-RiviereN, Warheit D, and Yang $H$ (2005b). "Principles for characterising the potential human health effects from exposure to nanomaterials: elements of a screening strategy". Particle and Fibre Toxicology 2:8.

[45] Oberdörster G, Oberdörster E and Oberdörster J (2005a). "Nanotoxicology: an emerging discipline from studies of ultrafine particles";Environmental Health Perspectives 113(7):823-839.

[46] Oberdörster G, Sharp Z, Atudorei V, Elder A, Gelein R, Kreyling W,. 2004.Translocation of inhaled ultrafine particles to the brain. Inhal Toxicol 16:437-445.

[47] Oberdorster, Eva, Shiqian Zhu, T. Michelle Blickley ,Patricia McClellan-Green , Mary L. Haasch .2006. Ecotoxicology of carbon-based engineered nanoparticles: Effects of fullerene(C60) on aquatic organisms. Carbon $44:$ 1112-1120 .

[48] Oberdoster (2004) .Manufactured Nanomaterials (Fullerenes, C60) Induce Oxidative Stress in the Brain of Juvenile Largemouth Bass. VOLUME 112 | NUMBER 10 | July 2004 • Environmental Health Perspectives

[49] Peters, A., Wichmann, H. E., Tuch, T., Heinrich, J., and Heyder, J. (1997). Respiratory effects are associated with the number of ultrafine particles. Am.J.Respir.Crit Care Med. 155, 1376-1383.

[50] Reynold Sequeira, Ash Genaidy, Richard Shell ,Waldemar Karwowski ,Gary Weckman ,Sam Salem (2006)The Nano Enterprise: A Survey of Health and Safety Concerns, Considerations, and Proposed 
Improvement Strategies to reduce Potential Adverse Effects ., Human Factors and Ergonomics in Manufacturing, Vol. 16 (4) 343-368 .

[51] Ringwood, A, Gonsalves, K, Khambhammettu, S, (2005)Characterization of nanoparticle risks in aquatic organisms. Deparment of Biology, UNC-Charlotte, Charlotte, NC, USA Department of Chemistry, UNC-Charlotte, Charlotte, NC, USA

[52] Rojo, Concepcion, Elin Ellertsdottir, Hans-Martin Pogoda And Dirk Meyer(2001) The gene schmalspur functions in mesoderm formation in zebrafish, and interacts with notail and spadetail . Int. J. Dev. Biol. 45 (S1): S157-S158 .

[53] Rouse J, Yang J, Barron A, Monteiro-Riviere N (2006). "Fullerene-based amino acid nanoparticle interactions with human epidermal keratinocytes". Toxicology In Vitro. In Press

[54] Sarah B.Lovern and Rebecca Klapper (2006) Daphnia magna mortality when exposed to titanium dioxide and fullerene (c60) nanoparticles. Environmental Toxicology and Chemistry, Vol. 25, No. 4, pp. 1132-1137.

[55] Savic R, Luo L, Eisenberg A, Maysinger D (2003). "Micellar nanocontainers distribute to defined cytoplasmic organelles". Science 300:615-618

[56] Sayes C, Fortner J, Guo W, Lyon D, Boyd A, Ausman K, Tao Y, Sitharaman B, Wilson L, Hughes, J, West, J., Colvin, V .2004.The differential cytotoxicity of water-soluble fullerenes". Nanolett. 4:1881-1887.

[57] Sayes C, Fortner J, Guo W, Lyon D, Boyd A, Ausman K, Tao Y, Sitharaman B, Wilson L, Hughes J, West J, Colvin V (2004). "The differential cytotoxicity of water-soluble fullerenes". Nanolett. 4, 1881-1887.

[58] Sayes C, Fortner J, Guo W, Lyon D, Boyd A, Ausman K, Tao Y, Sitharaman B, Wilson L, Hughes J, West J, Colvin V (2004). "The differential cytotoxicity of water-soluble fullerenes". Nanolett. 4, 1881-1887

[59] Service R.F. 2004. Nanotechnology grows up. Science 304:1732-1734.

[60] Service R.F. 2005. Calls rise for more research on toxicology of nanomaterials [Editorial]. Science 310:1609.

[61] Shigeru Deguchi , Rossitza G.Alargova and Kaoru Tsujii (2001)Stable disepersion of fullerenes, C60 and C70 in water, preparation and characterization. Langmuir,176013-6017.

[62] Sondi, I \& Salopek-Sondi, B. 2004. Silver nanoparticles as antimicrobial agent: a case study on E.coli as a model for Gram-negative bacteria. J. Colloid Interface Sci.275: 177-182.

[63] Stone,V. ,F. Fernandes, A.T. Ford and N. Christofi. Suggested strategies for the ecotoxicology testing of nanoparticles .2006. in Mater.res.Soc.Symp.Proc. 895 :0.31-0.36.

[64] Toxicity of titanium dioxide nanoparticles to rainbow trout (Oncorhynchus mykiss): Gill injury, oxidative stress,and other physiological effects Gillian Federici, Benjamin J. Shaw, Richard D. Handy* Aquatic Toxicology 84 (2007) 415-430

[65] Wamer W, Yin J, Wei R (1997). "Oxidative damage to nucleic acids photosensitized by titanium dioxide". Free Radical Biol Med 23:851-858.

[66] Warheit D, Everitt J. 2004. Assessing the biological and environmental risks of nanoparticles. 43rd Society of Toxicology Annual Meeting, Baltimore, MD, USA, March 21-25, p 1850.

[67] Warheit DB, Laurence BR, Reed KL, Roach DH, Reynolds GAM, Webb TR. 2004. Comparative pulmonary toxicity assessment of single-wall carbon nanotubes in rats. Toxicol Sci 77:117-125.

[68] Wilson et al., 2002 Wilson, M. R., Lightbody, J. H., Donaldson, K., Sales, J., and Stone, V. (2002). Interactions between ultrafine particles and transition metals in vivo and in vitro. Toxicol.Appl.Pharmacol. 184, 172-179.

[69] Wolfgang, L. (2004). Industrial applications of nanomaterials: Chances and risks-Technological analysis. Dusseldorf, Germany: VDI Technologiezentrum GmbH. Retrieved between Feb. 15 and Mar. 15, 2005, from hwww.nano.sdu.dk/pdf/ nanosafe.pdf

[70] Yamago S, Tokuyama H, Nakamura E, Kikuchi K, Kananishi S, Sueki K, et al. 1995. In vivo biological behavior of a water-miscible fullerene: $14 \mathrm{C}$ labeling, absorption, distribution, excretion and acute toxicity.Chem Biol 2:385-389.

[71] Yamakoshi Y, Umezawa N, Ryu A, Arakane K, Miyata N, Goda Y, Toshiki M,Tetsuo N (2003). "Active oxygen species generated from photoexcited fullerene (C60) as potential medicines: 02- versus 02." Journal of American Chemical Society 125(42)12803-12809.

[72] Yamawaki H, Iwai N. 2006. Cytotoxicity of water soluble fullerene in vascular endothelial cells. Am J Physiol Cell Physiol 290:C1495-C502.

[73] Yang L, Watts DJ. 2005. Particle surface characteristics may play an important role in phytotoxicity of alumina nanoparticles. Toxicol Lett 158: 122-132.

[74] Zhang A and Sun Y (2004). "Photocatalytic killing effect of $\mathrm{TiO}_{2}$ nanoparticles on Ls-174-t human colon carcinoma cells." World Journal of Gastroenterology 10 (21):3191-3193. 
Radhika Rajasree et al : Studies on the Toxicological Effects of Engineered...

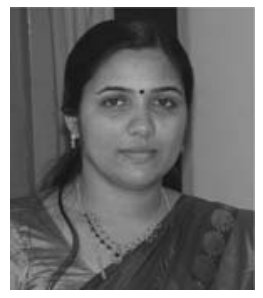

Dr.Radhika Rajasree is working as Scientist- $C$ and Group Head in Centre for Ocean Research, Sathyabama University. She took her Ph.D in Deep sea faunal biodiversity from Cochin University of Science \& Technology .She has twelve years of research / teaching experience in the field of Marine Biology and Ocean Biodiversity Assessment. Currently She works on Marine Nanoparticle Toxicity Assessment as Principal Investigator DBT,Govt. of India funded project and acts as CO-PI in DST sponsored projects. She has published papers in 4 international journals 9 national journals and 14 international/national conferences. 